\title{
Unique Functional Properties of On and Off Pathways in the Developing Mammalian Retina
}

\author{
Guo-Yong Wang, Lauren C. Liets, and Leo M. Chalupa \\ Section of Neurobiology, Physiology, and Behavior, Division of Biological Sciences and Ophthalmology Department, \\ School of Medicine, University of California, Davis, Davis, California 95616
}

In the mature retina, the dendrites of On and Off ganglion cells are segregated into separate sublaminas of the inner plexiform layer, but early in development these processes are multistratified, ramifying more widely within this synaptic layer. The dendritic pattern exhibited by immature ganglion cells suggests that there may be a functional convergence of On and Off pathways in the developing retina, but previous studies have provided evidence against this. Here we demonstrate by patchclamp recordings and dye filling that ganglion cells with multistratified dendrites respond to the onset, as well as the offset, of light. We further show that, in the dark-adapted retina, the glutamate analog 2-amino-4-phosphonobutric acid abolishes On and Off discharges in ganglion cells with multistratified dendrites. In contrast, in cells with stratified dendrites, this drug selectively blocks On responses. These findings provide evidence for unique functional attributes of On and Off pathways in the developing retina. The properties of immature ganglion cells documented here have important implications for the roles ascribed to neuronal activity in refining connections during the early development of the visual system.

Key words: development; retinal ganglion cell; APB; dendritic stratification; On and Off pathways; retina; visual system
The pathways that signal light increments are segregated from those that signal light decrements in the mature retina. Thus, the axons of On-cone and Off-cone bipolar cells terminate in two distinct strata of the inner plexiform layer (IPL) in which they form synapses with the dendrites of On and Off retinal ganglion cells (Famiglietti and Kolb, 1976; Nelson et al., 1978). In contrast, early in development, the dendritic processes of ganglion cells ramify throughout the IPL (Dann et al., 1988; Maslim and Stone, 1988; Ramoa et al., 1988). What underlies the gradual retraction of initially multistratified ganglion cell dendrites remains to be established. It has been shown, however, that treating the postnatal cat retina with the glutamate analog 2-amino-4phosphonobutric acid (APB), which in the mature retina hyperpolarizes On-cone bipolar cells and rod bipolar cells thereby preventing their release of glutamate (Slaughter and Miller, 1981; Bolz et al., 1984; Müller et al., 1988), results in a much higher than normal incidence of ganglion cells with multistratified dendrites (Bodnarenko and Chalupa, 1993; Bodnarenko et al., 1995). Interestingly, it is not activity per se that shapes this developmental process because the formation of stratified ganglion cells is not perturbed by intraocular TTX injections (Dubin et al., 1986; Wong et al., 1991) or by visual deprivation (Leventhal and Hirsch, 1983; Lau et al., 1990). Rather, the available evidence suggests that glutamate-mediated activity is the key factor in regulating ganglion cell dendritic stratification patterns.

To explain how synaptic activity could regulate the stratifica-

Received Feb. 5, 2001; revised March 21, 2001; accepted March 29, 2001.

This research was supported by National Institutes of Health Grant EY03991, National Science Foundation Grant IBN12593, and a Core grant from the National Eye Institute of the National Institutes of Health. We thank Cara J. Wefers for technical assistance and Dr. Jack Werner for measuring the intensity and background of the light stimuli.

G.-Y.W. and L.C.L contributed equally to this work.

Correspondence should be addressed to Leo M. Chalupa, Section of Neurobiology, Physiology, and Behavior, University of California, Davis, Davis, CA 95616. E-mail:1mchalupa@ucdavis.edu.

Copyright () 2001 Society for Neuroscience $0270-6474 / 01 / 214310-08 \$ 15.00 / 0$ tion of ganglion cell dendrites, a model was formulated stipulating that On- and Off-cone bipolar cell axons selectively innervate the multistratified dendrites of immature ganglion cells (Bodnarenko et al., 1995). In line with this idea, recent studies have shown that the axon terminals of On- and Off-cone bipolar cells form their stratified projection patterns in a remarkably precise manner, without any initial period of intermingling (Miller et al., 1999; Günhan-Agar et al., 2000). Moreover, electrophysiological recordings have reported that very few ganglion cells in the developing cat retina respond with On-Off discharges to flashing spots of light at a time when multistratified cells would be expected to be plentiful (Dubin et al., 1986; Tootle, 1993). However, these studies relied on extracellular recordings, a technique that does not allow one to relate structure to function. Thus, it remains to be established whether multistratified ganglion cells in the developing retina respond to both light onset and offset. If this were the case, such an outcome would indicate that individual multistratified ganglion cells are innervated by both On-cone and Off-cone bipolar cells. On the other hand, if multistratified ganglion cells respond only to the onset or offset of light, as reported by the previous extracellular recording studies, this would argue against such dual innervation by the two types of cone bipolar cells. One objective of the present study was to resolve this issue unequivocally. For this purpose, we assessed the discharge patterns of developing ganglion cells to flashing spots of light by whole-cell patch recordings and dye filling of these neurons.

Treating the developing retina with APB perturbs the stratification of On and Off retinal ganglion cells to an approximately equal degree (Bodnarenko and Chalupa, 1993; Bodnarenko et al., 1995; Bisti et al., 1998). This finding was unexpected because Off-cone bipolar cells are not APB sensitive. Although the development of metabotropic glutamate receptors (mGluRs) has not been investigated in the ferret retina, in the rodent it has been reported that all of the metabotropic receptor subtypes with the exception of mGluR3 are expressed early in postnatal develop- 
ment (Brandstätter et al., 1998). Also, recordings from isolated retinal ganglion cells of postnatal cats have shown that APB application does not directly influence the membrane properties of these neurons (Liets and Chalupa, 1996). As yet, however, the effects of this glutamate agonist on On and Off ganglion cell responses in the intact developing retina remain to be established. The second objective of the present study was to determine whether APB application affects the visual responses of immature ganglion cells, with multistratified dendrites, in a manner equivalent to that observed in ganglion cells with stratified dendrites.

\section{MATERIALS AND METHODS}

Retinal preparation. Retinas were obtained from ferrets (Marshall Farm USA, North Rose, NY) ranging in age from postnatal day 21 (P21) to P55, with the day of birth denoted as P0. All animals were dark-adapted overnight before the recordings. After a lethal dose of barbiturate (Nembutal, $200 \mathrm{mg} / \mathrm{kg}$, i.p.), the eyes were removed and placed in oxygenated $\mathrm{L} 15$ medium at $37^{\circ} \mathrm{C}$ for $12 \mathrm{~min}$. The retinas were then carefully peeled from the eyecup and stored at room temperature in Eagle's minimal essential medium (EMEM), continuously bubbled with $95 \%$ oxygen and $5 \% \mathrm{CO}_{2}$. A small piece of retina was placed ganglion cell layer up in the recording chamber and stabilized with an overlying piece of filter paper. A $2 \mathrm{~mm}$ hole in the filter paper provided access for the recording electrode. Cells were visualized through a $40 \times$ objective mounted on a fixed-stage upright epifluorescence microscope (Nikon, Tokyo, Japan). Infrared goggles were used to visualize the tissue on the dissecting and recording microscopes and to maneuver in the recording room. Lightemitting diodes (LEDs) $(850 \mathrm{~nm})$ were used to provide light to the dissecting microscope while the illumination from the recording microscope was passed through an $\geq 850 \mathrm{~nm}$ cut filter.

During recordings, the retina was perfused continuously with EMEM $(1.5 \mathrm{ml} / \mathrm{min})$ through a gravity-fed line, heated with a Peltier device, and continuously bubbled with $95 \%$ oxygen and $5 \% \mathrm{CO}_{2}$. A calibrated thermocouple monitored the temperature in the recording chamber, maintained at $35^{\circ} \mathrm{C}$. Recordings from individual cells usually lasted 30-120 min, and retinal segments from which recordings were made typically remained viable for $8-12 \mathrm{hr}$. Patch electrodes were filled with a solution containing $140 \mathrm{~mm} \mathrm{KCl}, 10 \mathrm{~mm}$ HEPES, $0.5 \mathrm{~mm}$ EGTA, 0.5 $\mathrm{mg} / \mathrm{ml}$ nystatin, $2.5 \mathrm{mg} / \mathrm{ml}$ Pluronic-F68, and $0.5 \%$ Lucifer yellow, $\mathrm{pH}$ 7.4. By the end of the experiment, the soma and the dendritic arborizations were usually completely filled, suggesting that recordings were made in the whole-cell configuration. Once complete cell filling was achieved, the retina was removed and fixed in $4 \%$ paraformaldehyde for $6-8 \mathrm{hr}$ at $4^{\circ} \mathrm{C}$.

Morphological analysis. Recorded cells were visualized and identified as ganglion cells before the electrode was withdrawn, and only neurons unequivocally identified as retinal ganglion cells were included in this study. Such identification was made on the basis of the morphological properties described by Wingate et al. (1992), including the presence of an axon in the nerve fiber layer, as well as the ability of cells to fire repetitive action potentials. Images of the labeled cells were taken in the whole-mount configuration with a Bio-Rad (Hercules, CA) MRC1024ES confocal microscope and reconstructed using the Bio-Rad computerized imaging system CoMOS (version 7.0), and cell class was determined from these images. Dendritic stratification was assessed by one of two methods. (1) In retinal whole mounts, the thickness of the IPL and the inner and outer borders of this synaptic layer were determined with Nomarski optics and quantified using a motorized focus controller (MFC-2000; Applied Scientific Instruments, Eugene, OR). The extent and depth of the dendrites was determined by focusing on the tips of these processes and reading a calibrated measure on the focus controller. (2) Retinal tissue containing the Lucifer yellow-filled cell from which recordings were made was reacted with an antibody for tyrosine hydroxylase, which recognizes dopaminergic amacrine cells (Chemicon, Temecula, CA). The processes of these interneurons stratify at the outer edge of the IPL, providing a convenient marker for this border (Tagawa et al., 1999). Images of the cross-section were taken on the confocal microscope. The width of the IPL was established using the red band of labeled amacrine cell processes and Nomarski images of the same crosssection. The position and extent of labeled dendrites was then referenced with respect to these retinal landmarks. The IPL was divided into On and Off sublaminas using commonly accepted standards in which the inner three-fifths is considered On and the outer two-fifths Off (Famiglietti and
Kolb, 1976; Nelson et al., 1978; Wong and Oakley, 1996). Both methods gave equivalent results and, because the former was less labor intensive, it was used more frequently. Cells with dendrites entirely confined to one or the other sublamina were consider to be stratified, whereas those with dendritic processes ramifying in both sublaminas were considered as multistratified.

Electrophysiology. Patch pipettes with a tip resistance between 3 and 7 $\mathrm{M} \Omega$ were pulled from thick-walled 1.5-mm-outer diameter borosilicate glass on a Sutter Instruments (Novato, CA) puller (model P-97). Currentclamp recordings were made with an Axopatch 200B patch-clamp amplifier (Axon Instruments, Foster City, CA). The data were low-pass filtered at rates between 1 and $2 \mathrm{kHz}$ and digitized at rates between 1 and $4 \mathrm{kHz}$ before storage on an IBM computer for subsequent off-line analysis. Recordings were obtained by patching onto cells with clear, nongranular cytoplasm. High-resistance seals were obtained by moving the patch electrode onto the cell membrane and applying gentle suction. After formation of a high-resistance seal between the electrode and the cell membrane, transient currents caused by pipette capacitance were electronically compensated by the circuit of the Axopatch 200B amplifier. If, during the recording, the seal resistance dropped below $1 \mathrm{G} \Omega$, the recording was terminated. The series resistance was 7-16 $\mathrm{M} \Omega$. After attaining whole-cell configuration, the resting membrane potential was read off the amplifier. The value of the resting potential was monitored regularly throughout the recording, and if significant changes were observed, recordings were terminated.

Light stimulus. Light-evoked responses were obtained by delivering spots of light from three computer-controlled LEDs (having $\lambda d=463$, 569 , and $651 \mathrm{~nm}$ ) through the camera port. Spectral power was measured with a silicon photodiode and linear readout system (81 Optometer; United Detector Technology, Hawthorne, CA) and a spectroradiometerphotometer (PR703-A; Photo Research, Chatsworth, CA) scanning from 390 to $720 \mathrm{~nm}$ in $2 \mathrm{~nm}$ steps. These instruments were calibrated relative to standards of the National Institute of Standards and Technology. The number of quanta delivered to the retina was specified per receptor per second, assuming that the inner segments form the optical aperture (based on a diameter of $0.315 \mu \mathrm{m}$ ) (Weidman and Greiner, 1984). The photoreceptors were stimulated at very low intensities (9-174 quanta per receptor per second), clearly in the scotopic range based on reasonable assumptions available from other species (Soucy et al., 1998).

$A P B$ application. APB $(25-100 \mu \mathrm{M})$ was dissolved in EMEM and administrated to the retinal whole mount through a gravity-fed line, heated with a Peltier device, and continuously bubbled with $95 \%$ oxygen and $5 \% \mathrm{CO}_{2}$. A six-position rotary valve (Western Analytical Products, Murrieta, CA) was used to switch between bath and APB solutions. The APB perfusion normally lasted 20-30 min, and the washout lasted 40-60 $\min$.

Data analysis. Response latencies were measured from the onset or the offset of the light stimulus to the onset of membrane depolarization giving rise to the spike discharges. The peak firing rate was calculated by counting the number of spikes within a window that encompassed the highest firing rate and dividing the spike number by the duration of the window.

\section{RESULTS}

\section{Light responses of morphologically identified developing retinal ganglion cells}

Whole-cell patch-clamp recordings were made from 151 ganglion cells of dark-adapted ferret retinas ranging in age from P21 to P55. This carnivore is born in a relatively immature state, $\sim 42 \mathrm{~d}$ after conception, with eye opening normally occurring at P32. Thus, our earliest recordings were made $11 \mathrm{~d}$ before eye opening. This is well after the period of naturally occurring ganglion cell death (Henderson et al., 1988) and subsequent to the withdrawal of transient photoreceptor projections to the IPL (Johnson et al., 1999).

At all ages, the responses evoked by a flashing spot of light centered on the soma were brisk and reliable when a sufficient interval was allowed between stimulus presentations, usually 30-60 sec. At shorter interstimulus intervals, responses tended to rapidly decrease in magnitude with repeated stimulation.

Three types of response patterns were observed. Some cells 

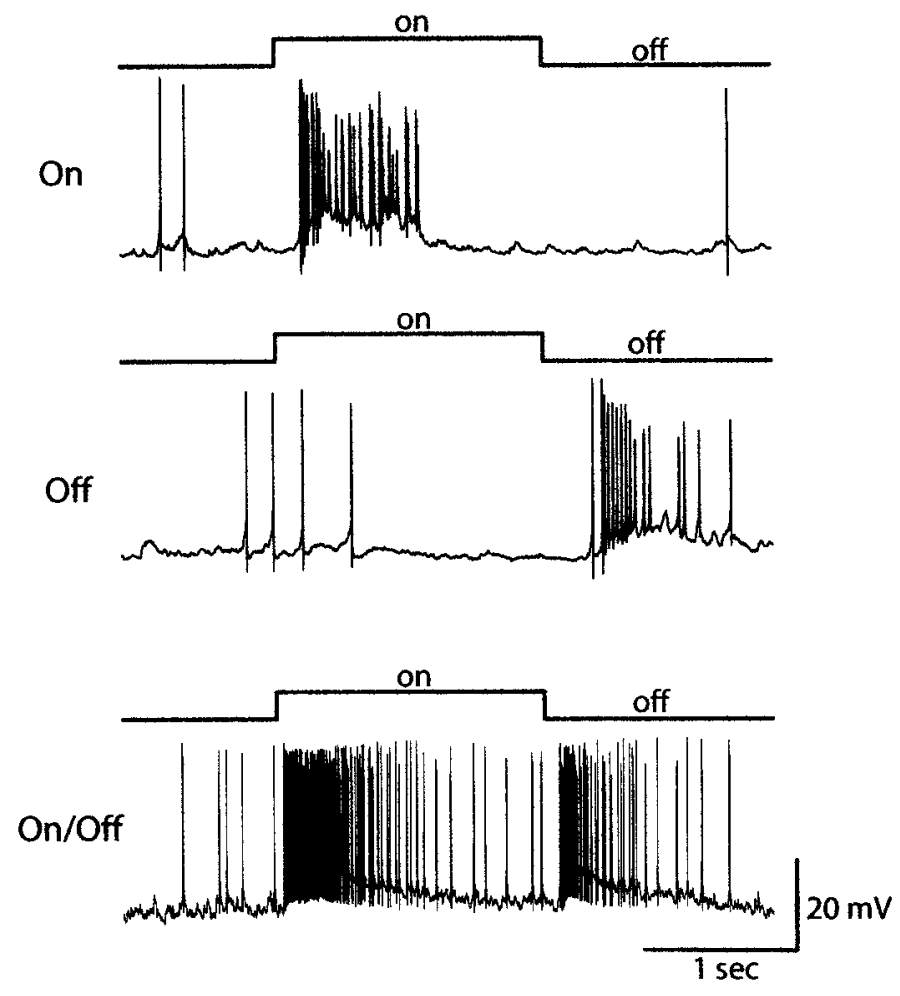

Figure 1. Whole-cell current-clamp recordings from three different ganglion cells in dark-adapted retinas. Light-evoked responses were obtained by delivering spots of light from three computer-controlled LEDs through the camera port. Three distinct response patterns were recorded: (1) On response, the cell responded only to light onset (top); (2) Off response, the cells responded only to light offset (middle); and (3) On-Off response, the cells responded to both light onset and offset (bottom). Recordings were made at $35^{\circ} \mathrm{C}$. The ages for these three cells were P32, $\mathrm{P} 30$, and P34, respectively.

discharged only to light onset, others only to light offset, whereas a third group yielded both On and Off responses. These three patterns are illustrated for different cells in Figure 1. As may by seen, bursts of action potentials were superimposed on a prolonged depolarization of the membrane potential after the onset and/or the cessation of the stimulus. For a given cell, the response pattern was invariant over the scotopic range of stimulus intensities (9-174 quanta per receptor per second) used in this study.

Although reliable responses were observed at all ages studied, there were significant increases in responsiveness with maturation. Age-related changes in response latency, defined as the time between stimulus onset or offset and the first spike in the response burst, as well as in average peak frequency, are depicted in Figure 2. These two response measures, obtained before and after eye opening, have been grouped separately for the On cells and Off cells (top panel) and the On-Off cells (bottom panel). As shown in Figure 2, On and Off responses became shorter in latency and had higher average peak firing rates after eye opening. Interestingly, the latencies of Off responses were significantly longer than those of On responses before and after eye opening. Presumably, this reflects the different circuitries of On and Off retinal pathways. Note that essentially the same pattern of results was obtained for the On and the Off cells as for the On-Off cells (compare top with bottom). Moreover, there were no significant differences in terms of response latency and average peak frequency between the On-Off cells and the cells that yielded only On or Off discharges.
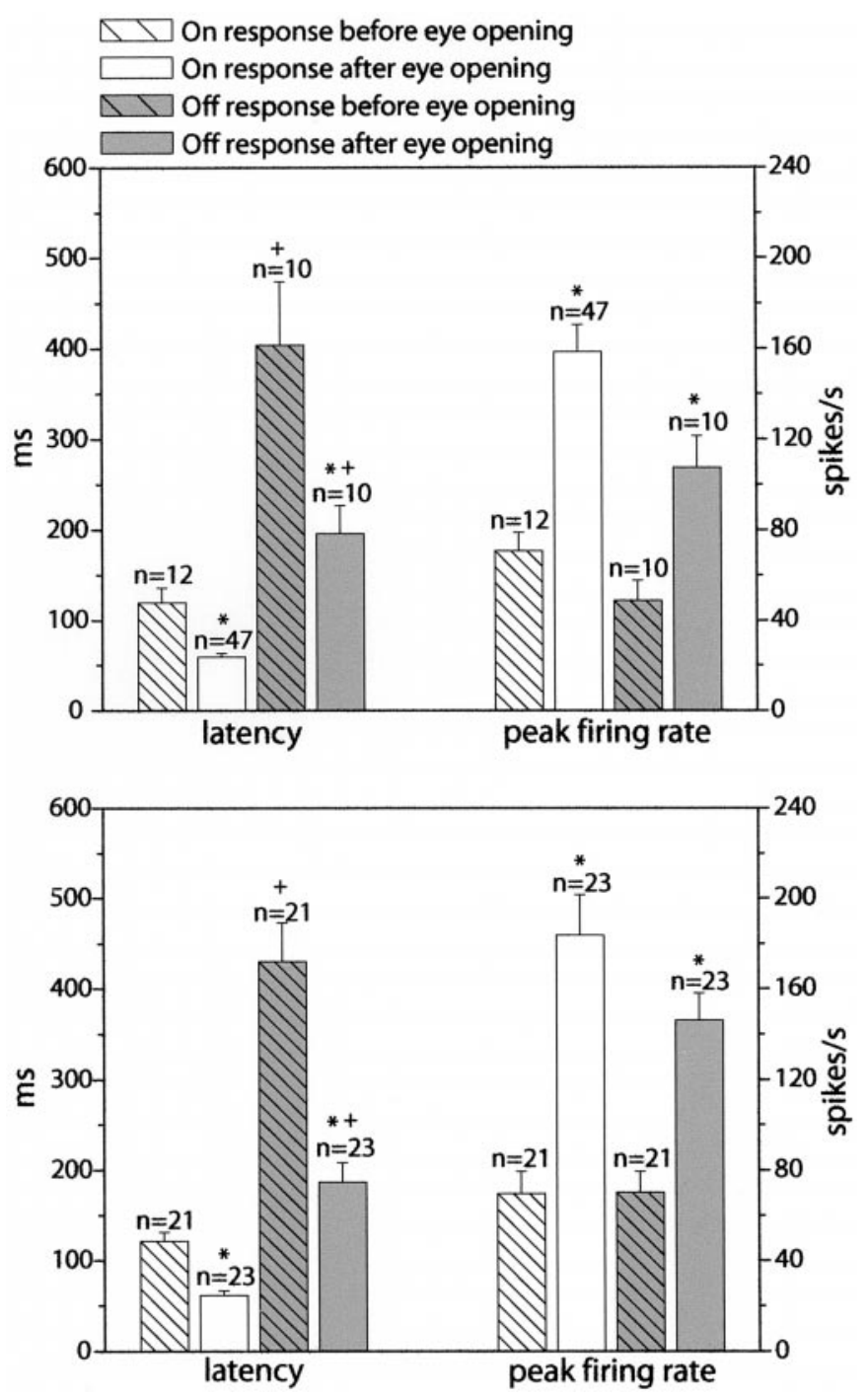

Figure 2. The latency and average peak firing rates of visual responses before and after eye opening are illustrated for On and Off cells (top), as well as for On-Off cells (bottom). Both latencies and average firing rates were significantly different before and after eye opening $\left({ }^{*} p<0.05\right.$, two-tailed $t$ test), with responsiveness increasing after eye opening. For all cell types, the latencies of the Off responses were significantly longer than those of the On responses $(+p<0.05$, two-tailed $t$ test $)$.

Although all three types of cells (On, Off, and On-Off) were encountered at all ages studied, the incidence of On-Off cells was found to be age related. As may be seen in Figure 3, in the youngest age group (P21-P29), $>70 \%$ of the recorded cells yielded On-Off discharges. A few days later (just after eye opening), the proportion of such neurons dropped to $<50 \%$. There was an additional decline in On-Off neurons over the next several weeks, so that in the oldest age group studied (P45-P55), such cells accounted for only $\sim 12 \%$ of the sample. At all ages, the remainder of the recorded cells were either On or Off, with the former being more prevalent. In the entire sample, 57 cells were On-Off, 65 cells were On, whereas 29 cells were Off.

Filling neurons with Lucifer yellow allowed us to identify the classes of the recorded cells based on well established morphological criteria (Wässle and Boycott, 1991; Wingate et al., 1992). (In some cases, removal of the patch electrode at the end of the recording period damaged the cell, precluding its morphological 


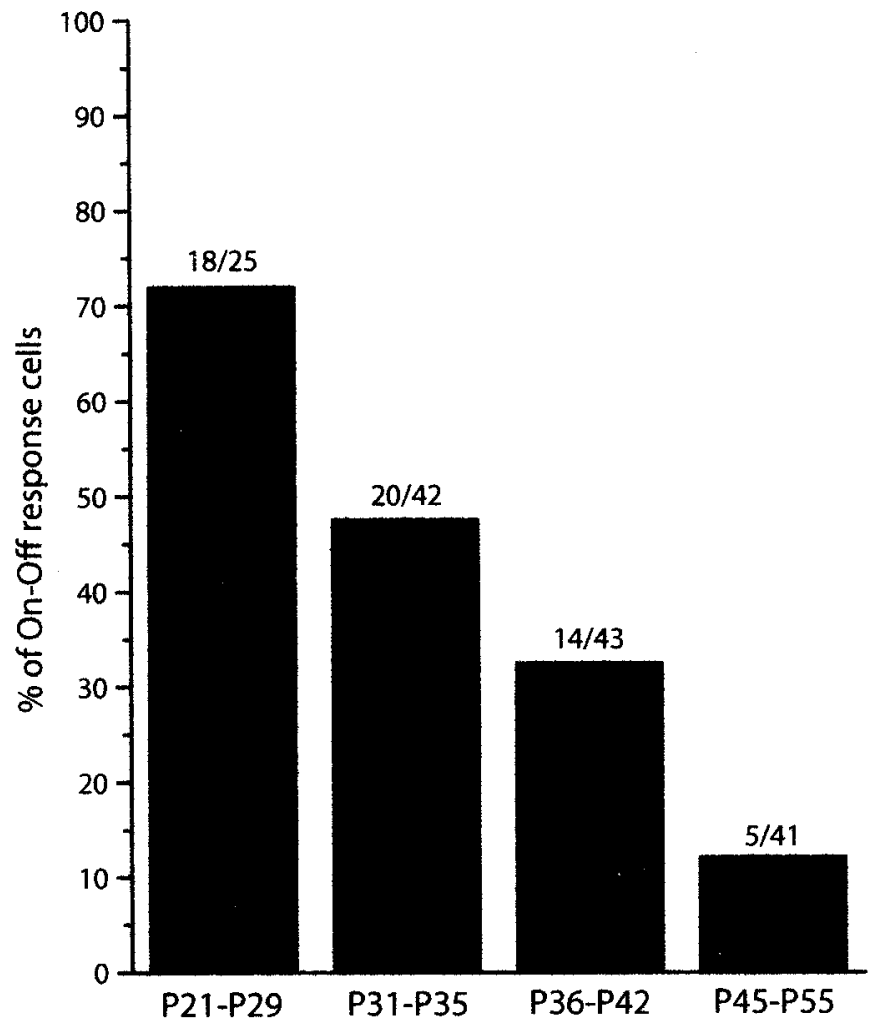

Figure 3. Age-related changes in the percentage of On-Off retinal ganglion cells. Note that, at the earliest age studied, the majority of cells yielded On-Off discharge patterns and that the proportion of such cells decreased progressively with maturity. The numbers at the top of the bars indicate the On-Off cells over the total sample studied in each age group.

identification.) This revealed that our sample of cells was comprised of all three major classes in the ferret retina: $\alpha, \beta$, and $\gamma$ (Fig. 4). The majority were $\beta$ cells $(n=57)$, with $\gamma(n=10)$ and $\alpha(n=4)$ cells being encountered much less frequently. It should be noted that these three major cell types could be unequivocally differentiated at all ages studied. This is particularly important with respect to the $\gamma$ cells because some of these neurons remain multistratified with On-Off responses in the mature retina (Fukuda et al., 1984).

When viewing individual cells, it often proved problematic to localize dendritic processes to a particular sublamina of the IPL without a clear reference point. This was resolved by labeling dopaminergic amacrine cells in the same sections that contained Lucifer yellow-filled ganglion cells. The dendrites of these amacrine cells stratify along the outer border of the IPL (Tagawa et al., 1999), whereas the inner border of this synaptic layer could be readily established by viewing the tissue with Nomarski optics. Figure 5 shows cross-sections taken on the confocal microscope of three $\beta$ cells with different stratification patterns. A cell with dendrites confined entirely to the On sublamina of the IPL is shown at the top, another cell with dendrites restricted to the Off sublamina is depicted in the middle, whereas in the bottom panel the dendrites of the cell span across both the On and Off sublaminas. Note also, in the middle panel, the labeled soma of a dopaminergic amacrine cell in the ganglion cell layer, just to the right of the Off cell.

In the mature retina, the dendritic stratification pattern of a ganglion cell provides a "morphological signature" of the response pattern to a flashing spot of light (Famiglietti and Kolb,
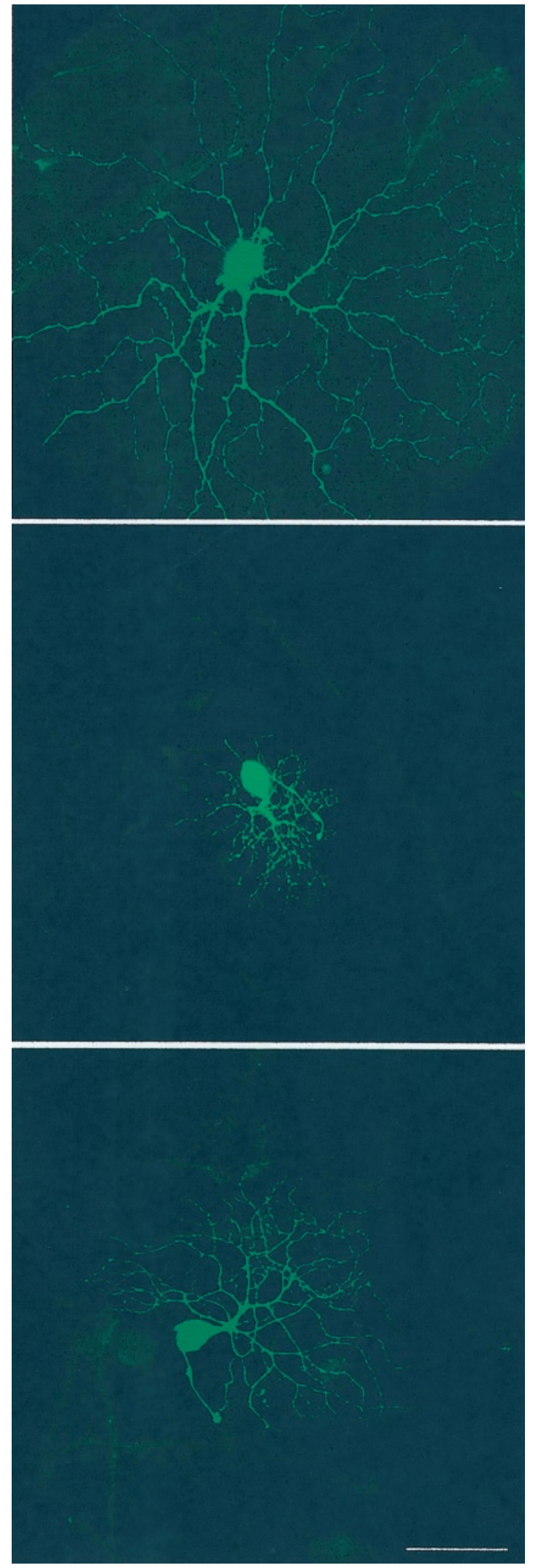

Figure 4. Recordings were made from three morphologically identified classes of ganglion cells: $\alpha$ (top), $\beta$ (middle), and $\gamma$ (bottom). Cells were filled with Lucifer yellow during the recordings, as described in Materials and Methods. Confocal microscopy was used to produce $x-y$ projections of three-dimensional reconstructed cells. Scale bar, $50 \mu \mathrm{m}$. Cells shown were from P42, P45, and P38 ferrets, respectively. 

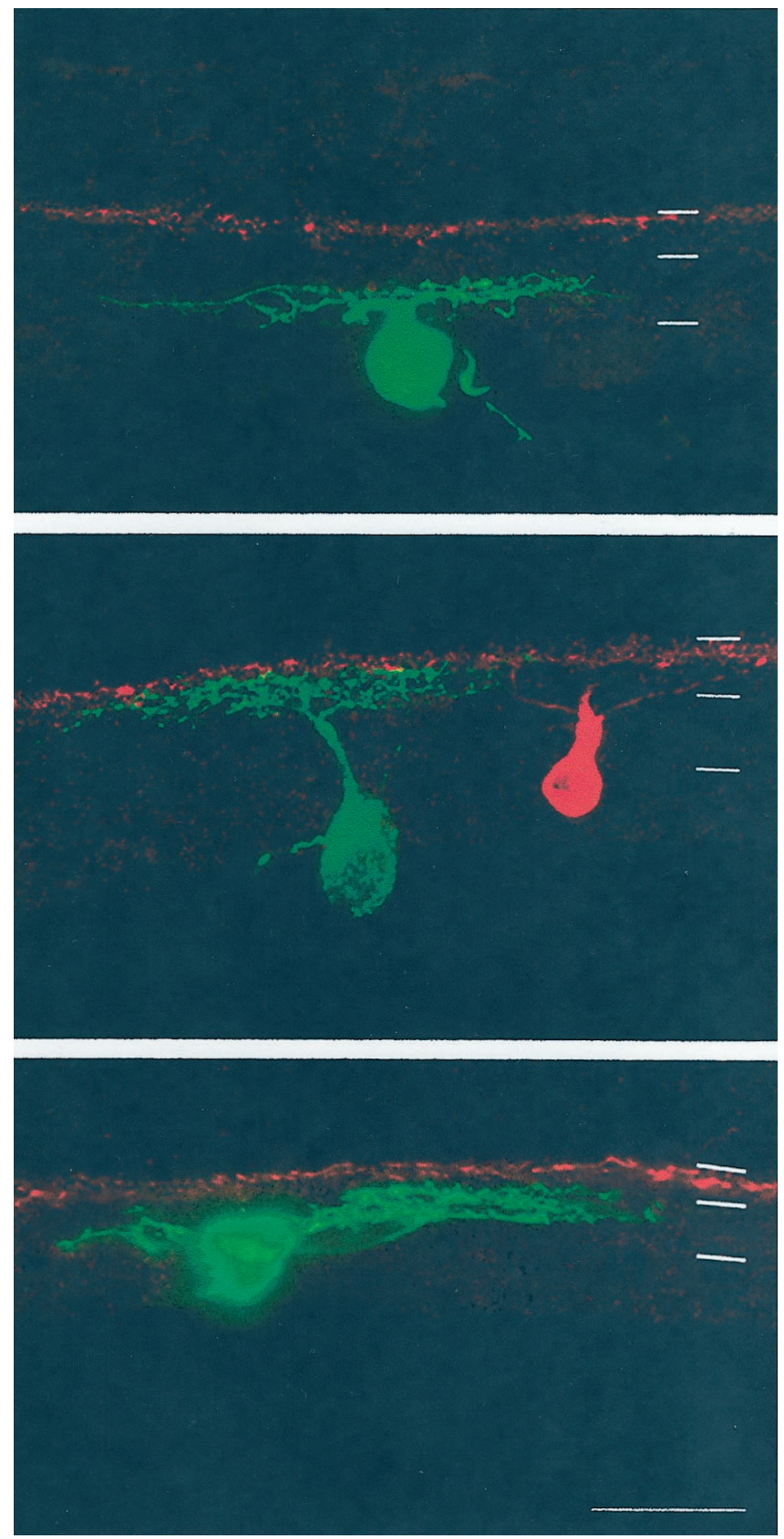

Figure 5. Stratification of developing ferret retinal ganglion cells. Crosssections of two ganglion cells with stratified dendrites (top and middle) and one ganglion cells with multistratified dendrites (bottom) are shown. The red band is comprised of the dendrites of dopaminergic amacrine cells labeled with Texas Red, denoting the outermost extent of the IPL. The On cell (top) had dendrites that terminated proximal to the cell soma in the inner three-fifths of the IPL. The Off cell (middle) had dendrites that were confined to the outer two-fifths of the IPL, near the red band of dopaminergic amacrine cell dendrites. The multistratified cell (bottom) had dendrites that ramified more widely, spanning both sublaminas of the IPL. White lines indicate the borders of the On and Off sublaminas. Scale bar, $50 \mu \mathrm{m}$. Cells shown were from P42, P45, and P29 ferrets, respectively.

1976; Nelson et al., 1978; Wässle and Boycott, 1991). This was also found to be the case for developing ganglion cells, although a notable exception was encountered. As expected, all of the cells that had their dendrites confined to the Off sublamina of the IPL responded only to the offset of light $(n=7)$, and all but one cell with dendrites confined to the On sublamina of the IPL re- sponded only to light onset (15 of 16). The exceptional neuron, recorded in a $\mathrm{P} 42$ retina, responded to light offset, although its dendrites were confined entirely to the On sublamina. Presumably, this reflects a developmental anomaly, with an Off-cone bipolar cell innervating the inappropriate portion of the IPL.

We were particularly eager to learn whether the On-Off cells were characterized by multistratified dendrites. The results show that this was indeed the case because cells with multistratified dendrites (25 of 32) commonly responded to both light onset and offset. Four such cells yielded only On responses and three others only Off responses. Of the 25 multistratified cells that yielded both On and Off discharges, one was an $\alpha$ cell, 21 were $\beta$ cells, and three were gamma cells.

We infer from these results that ganglion cells with multistratified dendrites are innervated early in development by On-cone and Off-cone bipolar cells. The finding that some ganglion cells with multistratified dendrites yielded only On or only Off responses could reflect the fact that one or the other cone bipolar cell input no longer formed functional synapses. Alternatively, dual innervation by cone bipolar cells may not be a universal property of all multistratified ganglion cells.

\section{Effects of APB application on the visual responses of developing ganglion cells in the dark-adapted retina}

We also characterized the functional properties of developing On and Off pathways by assessing the effects of APB on the discharge patterns of retinal ganglion cells. In the mature retina, this glutamate agonist hyperpolarizes On bipolar cells and rod bipolar cells, thereby preventing their release of glutamate (Slaughter and Miller, 1981; Bolz et al., 1984; Müller et al., 1988). However, nothing is known about the effects of APB on the visual responses of developing retinal ganglion cells. Our results indicate that this drug has different effects on more mature neurons with stratified dendrites than on ganglion cells with dendrites that are still in the multistratified state.

With respect to the cells with stratified dendrites, application of APB was found to differentially affect On and Off cells. Thus, in the dark-adapted retina, the responses of all On cells $(n=10)$ were blocked by application of this drug, whereas the responses of Off cells were resistant to APB (six of seven neurons). These observations indicate that, after segregation of On-Off retinal pathways has been established, the Off pathway is APB resistant, whereas the On pathway is sensitive to this glutamate analog.

In contrast, APB blocked both On and Off responses in multistratified ganglion cells. Thus, in 15 of 18 On-Off cells, all responses were abolished, whereas in three such cells, APB blocked On responses and reduced but did not entirely eliminate Off responses. This demonstrates that On, as well as Off, pathways are APB-sensitive in ganglion cells with multistratified dendrites. Examples of the effects of APB application on the responses of On, Off, and On-Off cells are shown in Figure 6.

To determine whether the effects of APB application on the light-evoked responses of developing retinal ganglion cells varied with concentration of the drug, we tested a range of concentrations $(25-100 \mu \mathrm{M})$ on all three cell types. The effect of APB on On responses was consistent across this range, with On responses being blocked at even the lowest concentration. Likewise, the On and Off responses of multistratified cells were also blocked at low concentrations of APB. Moreover, the light-evoked responses of Off cells were resistant to APB, even at the highest concentration tested (Fig. 6). These findings indicate that the effects of APB we observed cannot be explained by differential sensitivity of the 

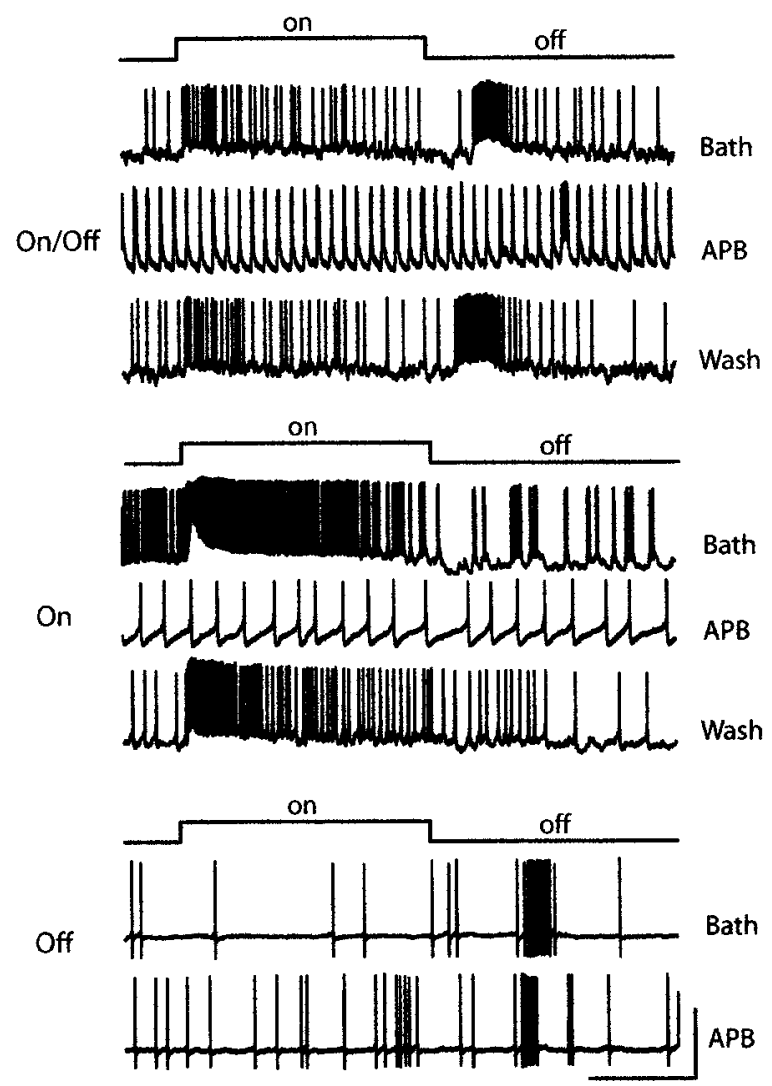

Figure 6. Whole-cell current-clamp recordings show the effect of APB on the light-evoked responses of ganglion cells in the dark-adapted retina. Immature cells yield On-Off responses (top traces) that were blocked by APB $(25 \mu \mathrm{M})$. Likewise, the responses of On cells (middle traces) were also blocked by application of APB, even at low concentrations $(25 \mu \mathrm{M})$. In contrast, Off cell responses (bottom traces) were resistant to application of APB, even at high concentration $(100 \mu \mathrm{M})$. Light-evoked responses that were blocked by application of APB recovered when the drug was removed from the bath. Calibration: $1 \mathrm{sec}$, and 30 (top traces), 45 (middle traces), and 60 (bottom traces) $\mathrm{mV}$. Recordings were made at $35^{\circ} \mathrm{C}$. The ages for these three cells were P38, P42, and P50, respectively.

different cell types to this drug. Rather, the results demonstrate the presence of an APB-sensitive Off pathway in the developing ferret retina that innervates multistratified ganglion cells.

\section{DISCUSSION}

Our results provide evidence for two unique functional properties of On and Off pathways in the developing retina. First, we have shown that multistratified ganglion cells in the immature retina respond to both light onset and offset. Most likely, this reflects the convergence of On- and Off-cone bipolar cells. Such response patterns were unexpected because previous studies concluded, on the basis of extracellular recordings, that very few ganglion cells in the developing cat retina respond to both the onset and offset of light (Dubin et al., 1986; Tootle, 1993), at a time when many ganglion cells are still multistratified (Maslim and Stone, 1988; Bodnarenko et al., 1995). Conceivably, this could reflect a species difference because the previous studies were done on cats, whereas we recorded from ferret retinas. However, with extracellular recordings, one cannot assess both functional and structural properties of individual neurons. By filling cells from which recordings were made with Lucifer yellow, in the present study, we were able to directly relate On-Off responses to ganglion cells with multistratified dendrites.
It should be noted that we report a higher proportion of multistratified ganglion cells than previous studies on the developing ferret (Bodnarenko et al., 1999) and mouse (Tagawa et al., 1999; Bansal et al., 2000). Most likely, this reflects differences among laboratories as to the criteria used to identify a cell as multistratified. In the present study, we classified a cell as multistratified if any portion of its dendritic tree ramified in more than one sublamina of the IPL. Our physiological results provide validation of this criterion because the cells we classified as multistratified yielded On and Off responses. In contrast, other studies relying exclusively on morphological measures assessed stratification patterns based on the extent of the primary dendrites of the cell.

A second unique functional feature of the developing retina was demonstrated by the changing susceptibility observed in the Off pathway to APB application. Although this drug blocked both On and Off responses of multistratified ganglion cells, in cells with stratified dendrites, APB selectively abolished On responses. Because our recordings were made from dark-adapted retinas, only the rods were capable of responding to light. Rods transmit signals via rod bipolar cells to all amacrine cells, then to On- and Off-cone bipolar cells (by gap junctions and glycinergic synapses, respectively), which in turn innervate the dendrites of On and Off ganglion cells (Sharpe and Stockman, 1999). Recently, it has been reported that rod photoreceptors could also synapse directly on Off-cone bipolar cells. This was demonstrated by an immunoelectron microscopy study of the adult rat retina (Hack et al., 1999), and such a pathway has been also inferred from an electrophysiological study of a transgenic mouse coneless retina (Soucy et al., 1998). Additional study is required to determine whether a direct rod-Off-cone bipolar cell pathway is present in the ferret retina. If such a pathway does exist in the mature ferret, our results would suggest that it may be absent early in development when multistratified ganglion cells are abundant.

\section{Regulation of dendritic stratification by glutamate-mediated activity}

Previously, we showed that intraocular injections of APB prevented the normal stratification of retinal ganglion cell dendrites (Bodnarenko and Chalupa, 1993; Bodnarenko et al., 1995). Based on these observations, it was suggested that glutamate-mediated afferent activity regulates the stratification of multistratified ganglion cells. It was problematic to explain, however, how APB treatment could affect the stratification of On and Off ganglion cells to an approximately equal degree because, in the adult retina, this drug selectively blocks On-cone bipolar cells and rod bipolar cells, but not Off-cone bipolar cells (Bolz et al., 1984; Müller et al., 1988). The results of the present study offer a resolution of this puzzle. As shown here, both On and Off responses are blocked by APB application in multistratified ganglion cells. Thus, one would expect that treating the developing retina would perturb the stratification of On, as well as Off, retinal ganglion cell dendrites.

Electrophysiological recordings from mature animals that received intraocular injections of APB early in development have revealed the presence of many ganglion cells with On-Off responses (Bisti et al., 1998). In view of the results of the present study, the findings of Bisti et al. (1998) can be interpreted as showing that such early APB retinal injections caused a "maintenance" of ganglion cells with multistratified dendrites innervated by On- and Off-cone bipolar cells.

Recently, Tagawa et al. (1999) showed that, in mice lacking 
mGluR6, the stratification of ganglion cell dendrites was primarily normal. These authors viewed their findings as being at odds with the notion that dendritic stratification in developing ganglion cells is regulated by glutamate-mediated activity. However, because binding of APB to mGluR6 normally prevents the release of glutamate by bipolar cells, one might expect higher than normal levels of glutamate release by bipolar cells in knock-outs lacking this receptor. Thus, there is no reason to think that animals lacking mGluR6 should have a lower than normal incidence of ganglion cells with stratified dendrites. Indeed, it might be the case that stratification occurs earlier in the retina of such animals than in the wild-type mouse.

To explain how glutamate-mediated activity regulates the stratification of retinal ganglion cell dendrites, we proposed that an asymmetrical innervation of On- or Off-cone bipolar cells could "instruct" developing ganglion cells which dendritic process to retract and which to maintain (Bodnarenko et al., 1995). This model was in line with the results of extracellular recordings showing that few cells in the developing retina respond to both the onset and offset of light. The present study has revealed, however, that multistratified ganglion cells are commonly innervated by On and Off inputs. Moreover, in many cases, On and Off discharges appeared equally robust. Thus, it seems unlikely that an asymmetry of functional On and Off inputs could account for the elimination of exuberant dendritic processes in immature ganglion cells.

So how can one account for the role of afferent activity in the stratification of ganglion cell dendrites? One possibility is that glutamate release from bipolar cells triggers an intrinsic program in multistratified ganglion cells leading to the retraction of one or another set of their dendritic processes. This idea would be supported if it could be shown that the molecular composition of On and Off cells differs and that such differences are expressed in immature ganglion cells with multistratified dendrites. It may also be the case that signals from other types of retinal afferents contribute to this developmental event. In particular, it would be of interest to assess the impact of cholinergic inputs from amacrine cells because it has been shown that the processes of these retinal interneurons become stratified very early in development of the ferret retina (Feller et al., 1996).

\section{Implications for the role of activity in refinement of retinal projections}

In the mature ferret, retinal projections are segregated in the dorsal lateral geniculate nucleus into eye-specific laminas, as well as On and Off sublaminas. The formation of eye-specific projections occurs within the first 2 postnatal weeks (Linden et al., 1981), whereas segregated On and Off inputs are formed between the third and fourth postnatal week (Hahm et al., 1991). Both sets of connections are thought to be refined through activitymediated events, involving the correlated firing patterns of developing retinal ganglion cells (Feller, 1999; Wong, 1999).

To date, the studies dealing with the role of activity in the formation of retinal projection patterns have focused almost exclusively on "spontaneous" discharge patterns (Maffei and Galli-Resta, 1990; Meister et al., 1991). Such activity is considered spontaneous because it can be recorded even before photoreceptors have been generated. In particular, it has been shown that On and Off retinal ganglion cells exhibit spatially and temporally distinct firing patterns that may account for the formation of separate On and Off inputs to the geniculate nucleus in accordance with the Hebbian postulate (Wong and Oakley, 1996). The results of the present study suggest, however, that during the time when On and Off projections are being established, ganglion cells can respond to light, even before eye-opening. Thus, both spontaneous and light-evoked activity may contribute to the segregation of On and Off retinogeniculate pathways. In this respect, the formation of eye-specific layers within the dorsal lateral geniculate nucleus differs from the segregation of On and Off inputs because the former are established before any visual activity can be evoked in ganglion cells.

Our results also indicate that On-Off ganglion cells are prevalent in the developing retina during the time when On and Off retinogeniculate pathways are becoming segregated. Thus, the activity-mediated segregation of On and Off retinal inputs to the lateral geniculate nucleus would appear to reflect, at least during the initial phase, the contributions of a relatively limited subset of ganglion cells. As stratification of ganglion cell dendrites progresses, more cells could be recruited to this process, leading ultimately to the formation of segregated On and Off retinogeniculate inputs.

\section{REFERENCES}

Bansal A, Singer JH, Hwang BJ, Xu W, Beaudet A, Feller MB (2000) Mice lacking specific nicotinic acetylcholine receptor subunits exhibit dramatically altered spontaneous activity patterns and reveal a limited role for retinal waves in forming ON and OFF circuits in the inner retina. J Neurosci 20:7672-7681.

Bisti S, Gargini C, Chalupa LM (1998) Blockade of glutamate-mediated activity in the developing retina perturbs functional segregation of $\mathrm{ON}$ and OFF pathways. J Neurosci 18:5019-5025.

Bodnarenko SR, Chalupa LM (1993) Stratification of ON and OFF ganglion cell dendrites depends on glutamate-mediated afferent activity in the developing retina. Nature 364:144-146.

Bodnarenko SR, Jeyarasasingam G, Chalupa LM (1995) Development and regulation of dendritic stratification in retinal ganglion cells by glutamate-mediated afferent activity. J Neurosci 15:7037-7045.

Bodnarenko SR, Yeung G, Thomas L, McCarthy M (1999) The development of retinal ganglion cell dendritic stratification in ferrets. NeuroReport 10:2955-2959.

Bolz J, Wässle H, Thier P (1984) Pharmacological modulation of on and off ganglion cells in the cat retina. Neuroscience 12:876-886.

Brandstätter JH, Koulen P, Wässle H (1998) Diversity of glutamate receptors in the mammalian retina. Vision Res 38:1385-1397.

Dann JF, Buhl EH, Peichl L (1988) Postnatal dendritic maturation of $\alpha$ and $\beta$ ganglion cells in cat retina. J Neurosci 8:1485-1499.

Dubin MW, Stark LA, Archer SM (1986) A role for action-potential activity in the development of neuronal connections in the kitten retinogeniculate pathway. J Neurosci 6:1021-1036.

Famiglietti Jr EV, Kolb H (1976) Structural basis for ON-and OFFcenter responses in retinal ganglion cells. Science 194:193-195.

Feller MB (1999) Spontaneous correlated activity in developing neural circuits. Neuron 22:653-656.

Feller MB, Wellis DP, Stellwagen D, Werblin FS, Shatz CJ (1996) Requirement for cholinergic synaptic transmission in the propagation of spontaneous retinal waves. Science 272:1182-1187.

Fukuda Y, Hsiao CF, Watanabe M, Ito H (1984) Morphological correlates of physiologically identified Y-, X-, and W-cells in cat retina. J Neurophysiol 52:999-1013.

Günhan-Agar E, Kahn D, Chalupa LM (2000) Segregation of On and Off bipolar cell axonal arbors in the absence of retinal ganglion cells. J Neurosci 20:306-314.

Hack I, Peichl L, Brandstätter JH (1999) An alternative pathway for rod signals in the rodent retina: rod photoreceptors, cone bipolar cells, and the localization of glutamate receptors. Proc Natl Acad Sci USA 96:14130-14135.

Hahm JO, Langdon RB, Sur M (1991) Disruption of retinogeniculate afferent segregation by antagonists to NMDA receptors. Nature 351:568-570.

Henderson Z, Finlay BL, Wikler KC (1988) Development of ganglion cell topography in ferret retina. J Neurosci 8:1194-1205.

Johnson PT, Williams RR, Cusato K, Reese BE (1999) Rods and cones project to the inner plexiform layer during development. J Comp Neurol 414:1-12.

Lau KC, So KF, Tay D (1990) Effects of visual or light deprivation on the morphology, and the elimination of the transient features during development, of type I retinal ganglion cells in hamsters. J Comp Neurol 300:583-592.

Leventhal AG, Hirsch HV (1983) Effects of visual deprivation upon the 
geniculocortical W-cell pathway in the cat: area 19 and its afferent input. J Comp Neurol 214:59-71.

Liets LC, Chalupa LM (1996) The metabotropic glutamate agonist 2-amino-4-phosphonobutyric acid (APB) does not activate currents in postnatal retinal ganglion cells. NeuroReport 7:2873-2877.

Linden DC, Guillery RW, Cucchiaro J (1981) The dorsal lateral geniculate nucleus of the normal ferret and its postnatal development. J Comp Neurol 203:189-211.

Maffei L, Galli-Resta L (1990) Correlation in the discharges of neighboring rat retinal ganglion cells during prenatal life. Proc Natl Acad Sci USA 87:2861-2864.

Maslim J, Stone J (1988) Time course of stratification of the dendritic fields of ganglion cells in the retina of the cat. Dev Brain Res 44:87-93.

Meister M, Wong RO, Baylor DA, Shatz CJ (1991) Synchronous bursts of action potentials in ganglion cells of the developing mammalian retina. Science 252:939-943.

Miller ED, Tran MN, Wong GK, Oakley DM, Wong RO (1999) Morphological differentiation of bipolar cells in the ferret retina. Vis Neurosci 16:1133-1144.

Müller F, Wässle H, Voigt T (1988) Pharmacological modulation of the rod pathway in the cat retina. J Neurophysiol 59:1657-1672.

Nelson R, Famiglietti Jr EV, Kolb H (1978) Intracellular staining reveals different levels of stratification for on- and off-center ganglion cells in cat retina. J Neurophysiol 41:472-483.

Ramoa AS, Campbell G, Shatz CJ (1988) Dendritic growth and remodeling of cat retinal ganglion cells during fetal and postnatal development. J Neurosci 8:4239-4261.
Sharpe LT, Stockman A (1999) Rod pathways: the importance of seeing nothing. Trends Neurosci 22:497-504.

Slaughter M, Miller R (1981) 2-Amino-4-phosphonobutyric acid: a new pharmacological tool for retina research. Science 21:182-185.

Soucy E, Wang Y, Nirenberg S, Nathans J, Meister M (1998) A novel signaling pathway from rod photoreceptors to ganglion cells in mammalian retina. Neuron 21:481-493.

Tagawa Y, Sawai H, Ueda Y, Tauchi M, Nakanishi S (1999) Immunohistological studies of metabotropic glutamate receptor subtype 6-deficient mice show no abnormality of retinal cell organization and ganglion cell maturation. J Neurosci 19:2568-2579.

Tootle JS (1993) Early postnatal development of visual function in ganglion cells of the cat retina. J Neurophysiol 69:1645-1660.

Wässle H, Boycott BH (1991) Functional architecture of the retina. Physiol Rev 2:447-480.

Weidman TA, Greiner JV (1984) Histology of the ferret retina. Anat Anz 157:329-341.

Wingate RJ, Fitzgibbon T, Thompson ID (1992) Lucifer yellow, retrograde tracers, and fractal analysis characterise adult ferret retinal ganglion cells. J Comp Neurol 323:449-474.

Wong RO (1999) Retinal waves and visual system development. Annu Rev Neurosci 22:29-47.

Wong RO, Oakley DM (1996) Changing patterns of spontaneous bursting activity of on and off retinal ganglion cells during development. Neuron 16:1087-1095

Wong RO, Herrmann K, Shatz CJ (1991) Remodeling of retinal ganglion cell dendrites in the absence of action potential activity. J Neurobiol 22:685-697. 